\title{
Analysing nonsynonymous mutations between two Mycobacterium bovis strains with contrasting pathogenic profiles
}

\author{
Mercedes Bigi ${ }^{\mathrm{a}, 1}$, Cristina Lourdes Vazquez ${ }^{\mathrm{b}, 1}$, Ana Beatriz C Castelão ${ }^{\mathrm{c}, 1}$, \\ Elizabeth Andrea García ${ }^{\mathrm{b}}$, Angel A Cataldi ${ }^{\mathrm{b}}$, Mary Jackson ${ }^{\mathrm{d}}$, Michael McNeil ${ }^{\mathrm{d}}$, Marcelo Soria ${ }^{\mathrm{a}}$, \\ Martín J Zumárraga ${ }^{\mathrm{b}}$, Matias Cabruja ${ }^{\mathrm{e}}$, Gabriela Gago ${ }^{\mathrm{e}}$, Federico C Blanco ${ }^{\mathrm{b}}$, Christiane Nishibe ${ }^{\mathrm{f}}$, \\ Nalvo F Almeida ${ }^{\mathrm{f}}$, Flábio Ribeiro de Araújo ${ }^{\mathrm{g}, *}$, Fabiana Bigi ${ }^{\mathrm{b}, *}$ \\ ${ }^{a}$ Universidad de Buenos Aires, Facultad de Agronomía, Cátedra de Microbiología Agrícola, INBA-CONICET, Buenos Aires, Argentina \\ ${ }^{\mathrm{b}}$ Instituto de Biotecnología, IABIMO, CICVyA/INTA, Argentina \\ ${ }^{\mathrm{c}}$ Faculdade de Medicina Veterinária e Zootecnia, Universidade Federal de Mato Grosso do Sul, Campo Grande, Mato Grosso do Sul, Brazil \\ ${ }^{\mathrm{d}}$ Colorado State University, Dept. of Microbiology, Immunology and Pathology, USA \\ ${ }^{\mathrm{e}}$ Laboratory of Physiology and Genetics of Actinomycetes, Instituto de Biología Molecular y Celular de Rosario (IBR-CONICET), Facultad de Ciencias Bioquímicas y \\ Farmacéuticas, Universidad Nacional de Rosario, Rosario, Argentina \\ ${ }_{\mathrm{f}}^{\mathrm{f}}$ Faculdade de Computação, Universidade Federal de Mato Grosso do Sul, Campo Grande, Mato Grosso do Sul, Brazil \\ ${ }^{g}$ Embrapa Gado de Corte, Campo Grande, Mato Grosso do Sul, Brazil
}

\section{A R T I C L E I N F O}

\section{Keywords:}

Mycobacterium bovis

Genome

Virulence gene

Mutations

\begin{abstract}
A B S T R A C T
Mycobacterium bovis (M. bovis) is the causative agent of bovine tuberculosis, a chronic infectious disease that can affect cattle, other domesticated species, wild animals and humans. This disease produces important economic losses worldwide. Two M. bovis strains (04-303 and 534) have been isolated in Argentina. Whereas the 04-303 strain was isolated from a wild boar, the 534 strain was obtained from cattle. In a previous study, six weeks after infection, the 04-303 strain induced $100 \%$ mortality in mice. By contrast, mice infected with the 534 strain survived, with limited tissue damage, after four months. In this study we compared all predictive proteins encoded in both $M$. bovis genomes. The comparative analysis revealed 141 polymorphic proteins between both strains. From these proteins, nine virulence proteins showed polymorphisms in 04-303, whereas five did it in the 534 strain. Remarkably, both strains contained a high level of polymorphism in proteins related to phthiocerol dimycocerosate (PDIM) synthesis or transport. Further experimental evidence indicated that only mutations in the 534 strain have an impact on PDIM synthesis. The observed reduction in PDIM content in the 534 strain, together with its low capacity to induce phagosome arrest, may be associated with the reported deficiency of this strain to replicate and survive inside bovine macrophages. The findings of this study could contribute to a better understanding of pathogenicity and virulence aspects of $M$. bovis, which is essential for further studies aiming at developing new vaccines and diagnostic techniques for bovines.
\end{abstract}

\section{Introduction}

Mycobacterium bovis is the causative agent of bovine tuberculosis, a chronic infectious disease disseminated worldwide that mainly affects cattle, although it can also affect other domesticated species, wild animals and humans (Wobeser, 2009; Michel et al., 2003). M. bovis belongs to the Mycobacterium tuberculosis complex (MTBC), which traditionally consists of $M$. tuberculosis (the main agent of human tuberculosis), M. africanum, M. microti, M. canettii, M. bovis, M.caprae, $M$. pinnipedii and the recently incorporated species $M$. suricattae, $M$. mungi and $M$. orygis (Alexander et al., 2010; van Ingen et al., 2012). These species are genetically very similar, and share a conserved synteny as

\footnotetext{
* Corresponding authors.

E-mail addresses: mebigi@hotmail.com (M. Bigi), vazquez.cristina@inta.gob.ar (C.L. Vazquez), anabia_85@yahoo.com.br (A.B.C. Castelão),

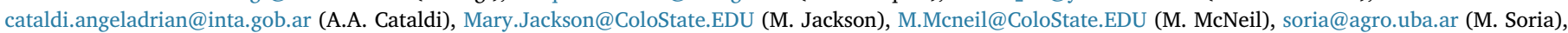
zumarraga.martin@inta.gob.ar (M.J. Zumárraga), cabruja@ibr-conicet.gov.ar (M. Cabruja), gago@ibr-conicet.gov.ar (G. Gago), blanco.federico@inta.gob.ar (F.C. Blanco), cnishibe@gmail.com (C. Nishibe), nalvo@facom.ufms.br (N.F. Almeida), flabio.araujo@embrapa.br (F.R.de Araújo), bigi.fabiana@inta.gob.ar (F. Bigi).

${ }^{1}$ These authors contributed equally to this study.
} 
well as $99.9 \%$ of the genome (Brosch et al., 2002).

Brosch et al. (Brosch et al., 2002) demonstrated that MTBC members have evolved from a common ancestor via successive DNA deletions, thus resulting in the present Mycobacterium speciation and in their differences in pathogenicity. Despite their high overall genetic relationship, MTBC species exhibit a wide range of phenotypes and host ranges. The deletion of genetic information, together with the presence of single nucleotide polymorphisms (SNP) across chromosomes of MTBC species, probably explains the different host ranges, virulence and immunopathology found among these species.

Garnier et al. (Garnier et al., 2003) published the complete genome sequence of $M$. bovis in June 2003, five years after the publication of the $M$. tuberculosis genome sequence (Cole et al., 1998). The genome of $M$. bovis and $M$. tuberculosis are more than $99.95 \%$ identical, but with seven deleted regions ranging from 1 kilobase $(\mathrm{kb})$ to $12.7 \mathrm{~kb}$. Thus, these gene deletions could account for the main evolutionary forces that have shaped the $M$. bovis genome. Indeed, many of the absent or altered genes in $M$. bovis are also missing or altered in M. leprae, an obligate intracellular pathogen that has undergone a significant reduction in its genome (Garnier et al., 2003).

A deeper knowledge of the mycobacterial virulence factors is essential for the development of new vaccines and drugs to help manage the disease and move towards a world free of tuberculosis.

The $M$. bovis 04-303 strain was isolated from a wild boar in the La Pampa province of Argentina in 2004, and characterized as spoligotype SB0140, with a Mycobacterial Interspersed Repetitive Units (MIRU) pattern of 232224263322 (Aguilar León et al., 2009; Nishibe et al., 2013). The M. bovis 534 strain, on the other hand was isolated from cattle in the Santa Fe province of Argentina, in 1997. This strain was characterized as spoligotype SB0140, with an MIRU pattern of 232224163322 (Aguilar León et al., 2009). In an experimental BALBc model of progressive pulmonary tuberculosis, mice infected with the 04-303 strain exhibited high mortality (Aguilar León et al., 2009). The animals developed a mild inflammatory response, followed by sudden pneumonia, with extensive necrosis. Conversely, mice infected with the 534 strain exhibited higher survival rates and limited tissue damage, with progressive expression of IFN- $\gamma$ and elevated expression of IL-4, TNF- $\alpha$ and iNOS. The 04-303 strain induced a significantly lower expression of these immune mediators. In another study where the researchers assessed the secretion of virulence factors as well as phagocytosis of both strains by J774A.1 macrophages, the 04-303 strain secreted more ESAT- 6 and CFP-10 than the genetically related strain 444, and was more phagocytized than BCG and even more than 444 strain (Vargas-Romero et al., 2016). In experimentally infected cattle, the 04-303 strain produced more severe lesions, in the evaluated organs, with granuloma and pneumonic areas, than the $M$. bovis strain, NCTC 10772 (Meikle et al., 2011). In a guinea pig model of $M$. bovis infection, the 04-303 strain was significantly more virulent than the NCTC 10772 strain (Meikle et al., 2011). Based on these results, the researchers characterized $M$. bovis $04-303$ as a highly virulent strain.

Considering the extreme pathogenic phenotype of the 04-303 strain and the attenuated phenotype of the 534 strain, we hypothesized that the differences in virulence could be attributable to nonsynonymous mutations in the coding sequences. With this in mind, we performed a comparative genomic analysis to identify nonsynonymous single nucleotide polymorphisms (NS-SNP) and insertions/deletions in the coding sequences of the M. bovis 04-303 and 534 strains. We used the complete genome of $M$. bovis AF2122/97 (Garnier et al., 2003) as reference.

\section{Material and methods}

\subsection{Bacterial strains and culture media}

M. bovis strains were grown in Middlebrook 7H9 medium (Difco Laboratories, 271310) supplemented with albumin (A) 0.5\%, dextrose
(D) $0.4 \%$, and pyruvate (P) $0.5 \%$ (M7H9-AD-P) or Middlebrook 7H10 (Difco Laboratories, 262,710) supplemented with AD-P. When necessary, $50 \mu \mathrm{g} / \mathrm{ml}$ hygromycin, $\mu \mathrm{g} / \mathrm{ml} 20$ kanamycin or Tween 80 (T80) $0.05 \%$ was added to the media.

The $M$. bovis $04-303$ and $M$. bovis 534 strains were isolated from a wild boar in a free-ranging field and from dairy cattle in the humid Pampas region, respectively, both in Argentina. The DNA from the isolates were extracted and purified as described by van Soolingen et al. (van Soolingen et al., 1991).

\subsection{Genome sequencing and annotation}

M. bovis 04-303 (Nishibe et al., 2013) and M. bovis 534 were deposited in the

DDBJ/EMBL/GenBank under the accession numbers GenBank: AVSW01000000 and JQEM00000000, respectively. The genome assembly showed 169 (average coverage of $27.3 \mathrm{x}$ ) and 72 contigs (average coverage of $50.5 \mathrm{x}$ ) for the 04-303 and 534 strains, respectively. Whole genome sequencing of 04-303 and 534 strains was performed on starter cultures from frozen seed stocks (Dr Zumárraga, personal communication).

The quality of the genome assemblies was assessed following the CheckM automated method (Parks et al., 2015). This method provides a broader set of marker genes that are specific to the position of a genome within a reference genome tree, as well as information about the collocation of these genes. According to the CheckM default thresholds, both assemblies exhibited a satisfactory quality. The coding densities of both genomes were within the expected range for bacterial genomes.

\subsection{Single nucleotide polymorphisms}

The open reading frames and protein sequences of the reference strain, AF2122/97 (LT708304.1), were compared with the whole genome of both strains. NS-SNPs were found using an in-house script written in Python and Translated BLAST: tblastn.

The algorithm tbBLASTn was used to retrieve NS-SNPs in the $M$. bovis genomes deposited in NCBI. The Query was a multifasta of the 30 selected sequences (S1) and subject was Mycobacterium bovis (taxid 1765), excluding $M$. bovis BCG (taxid 33892). The expected threshold was set up to $1 \mathrm{e}-6$.

\subsection{Virulence-related genes analysed}

This analysis was performed with all genes from both genomes, as published by Forrellad et al. (Forrellad et al., 2013) and Sassetti et al. (Sassetti et al., 2003) and/or with genes listed in the TubercuList database server (http://genolist.pasteur.fr/TubercuList). The analysis of conserved domains was done with ScanProsite (http://prosite.expasy. org/scanprosite/.) and CD search (https://www.ncbi.nlm.nih.gov/ Structure/bwrpsb/bwrpsb.cgi).

\subsection{Analysis of protein stability changes due to NS-mutations}

The STRUM method was used for predicting the fold stability change $(\Delta \Delta \mathrm{G})$ of virulence factors upon single-point NS-SNP mutations (http://zhanglab.ccmb.med.umich.edu/STRUM/).

\subsection{Lipid analyses}

Total lipids from bacterial cells were extracted following procedures described previously (Stadthagen et al., 2005). Briefly, cultures were grown to late exponential phase (optical density (OD) $600 \mathrm{~nm} \mathrm{0.8-1)}$ and total cell wall lipids extracted with chloroform:methanol. Fatty acid and mycolic acid methyl esters (FAMES and MAMEs, respectively) were derived from extractable lipids as described by Stadthagen et al. (Stadthagen et al., 2005). Lipids were analysed by TLC on silica gel 
60F254 by loading the same lipid quantities per lane $(100 \mu \mathrm{g})$. TLCs were developed in three different solvent systems and revealed by spraying with a CuSO4-phosphoric acid solution and heating. These experiments were repeated with five independent lipid samples of each M. bovis strain.

\subsection{Liquid chromatography-mass spectrometry (LC-MS) analysis}

Total lipids were analysed by LC/MS as described by Sartain et al. (Sartain et al., 2011). High-resolution Agilent 6220 TOF and Brucker micrOTOF-Q II mass spectrometers interfaced to a LC were used for the analysis. Data files were analysed with Agilent's Mass hunter workstation software (Version B.02.00, build 2.0.197.0) and software MZmine2 (Pluskal et al., 2010) to identify compounds using 'molecular feature extractor'.

The Agilent mass profiler program was used to compare all the lipids present in the samples. Most compounds were identified using the lipid database developed by Sartain et al. Compounds of interest were semi-quantified by comparing their relative abundance in the samples.

\subsection{Peripheral blood mononuclear cell (PBMC) isolation and monocyte- derived macrophages (BMDM) differentiation}

Peripheral blood samples were obtained from cattle selected from the experimental herd of INTA. All these animals tested negative for bovine tuberculosis infection according to the single intradermal tuberculin test and Interferon- $\gamma$ release test. A sample of blood $(50 \mathrm{~mL})$ was taken from each animal in sterile conditions and PBMCs were separated from heparinized blood by centrifugation over histopaque 1077 following the manufacturer's protocol. Monocytes were differentiated by culturing PBMCs on 24-well plates with coverslips (or not) containing RPMI 1640 complete medium supplemented with $10 \%$ of autologous plasma at $37^{\circ} \mathrm{C}$ and $5 \% \mathrm{CO}_{2}$. Adherent cells were maintained in culture for 5 days to obtain BMDMs. The cell viability was confirmed by trypan blue exclusion assay (data not shown). Sample collection and animal handling were done in compliance with the regulations of the Ethical Committee of INTA (CICUAE).

\subsection{BMDM infections}

M. bovis strains were cultured to exponential growth phase (OD $600 \mathrm{~nm}$ 0.4-0.6), harvested, washed and resuspended in RPMI medium. The bacterial suspensions were centrifuged at $900 \mathrm{~g}$ for $10 \mathrm{~min}$ to eliminate bacterial clumps in the pellets. The optical densities of the bacterial suspensions were adjusted to a multiplicity of infection (MOI) of 2. BMDMs were infected for $2 \mathrm{~h}$ at $37{ }^{\circ} \mathrm{C}$ and $5 \% \mathrm{CO}_{2}$ (uptake) and then washed three times to eliminate extracellular bacteria. Subsequently, BMDMs were incubated in RPMI medium supplemented with $10 \%$ of autologous plasma for $3,24,48$ and $72 \mathrm{~h}$ accordingly to the assay. Three and seven independent infections were performed for intracellular trafficking and for bacterial persistence assays, respectively.

Indirect immunofluorescence and confocal microscopy

Bovine BMDMs $\left(4 \times 10^{5}\right)$ were seeded in 24 well-plate with slides and then infected with the $M$. bovis strains at a MOI of 2 , as described before. After $72 \mathrm{~h}$ of infection, cells were fixed with $4 \%$ paraformaldehyde solution in PBS (PFA) for $30 \mathrm{~min}$ and quenched by incubation with $50 \mathrm{mM}$ glycine solution for $30 \mathrm{~min}$. The cells were then permeabilized with $0.05 \%$ saponin in PBS containing $1 \%$ bovine serum albumin (BSA) for $15 \mathrm{~min}$, followed by overnight incubation with rabbit anti-Mycobacterium primary antibody (Origene, USA) diluted 1:50 in PBS. Next, a secondary antibody anti-Rabbit conjugated to FITC (Jackson Immuno Research Labs, Inc.) diluted 1:600 in PBS was added and incubated for $1 \mathrm{~h}$. Subsequently, the cells were incubated with goat anti-LAMP-3 (Santa Cruz Biotechnology, Santa Cruz, CA) primary antibody diluted 1:50 in PBS for $2 \mathrm{~h}$. Secondary anti-goat antibody conjugated to cy3 (Jackson Immuno Research Labs, Inc.) was used diluted
1:600 in PBS. The cells were mounted with mounting medium (Dako, Denmark) and analysed by confocal microscopy using an SP5 AOBS confocal microscope (Leica Microsystems, Germany) at the Laboratorio Integral de Microscopía, CICVyA, INTA. Mycobacterial internalization was monitored using the fluorescence of FITC (green). LAMP-3 association with mycobacterial phagosomes was analysed in at least 500 cells using Fiji software (U.S. National Institutes of Health, Bethesda, MD) as described previously (Vázquez et al., 2017). The experiments were performed in duplicates in three independent experiments. The statistical analysis was performed using two-tailed Student's $t$-test.

\subsection{Recombinant $M$. bovis strains}

The esat- 6 gene was PCR amplified from genomic DNA of the 04-303 and 534 strains with specific primers, and cloned in NdeI and HindIII sites of pVV16 vector, which is a derivative of pMV261 (Stover et al., 1991) that allows His-tag fusion for expression in M. smegmatis. The inserts in the recombinant plasmids were sequenced; the results showed that the polymorphism of esat- 6 of $04-303$ and 534 deposited in the DDBJ/EMBL/GenBank were maintained in the recombinant plasmids. The recombinant plasmids PVV16-ESAT6 04-303 and PVV16-ESAT6 534 were used to transform the 534 strain. The recombinant 534 strains were selected in 7H10-AD-P medium containing $50 \mu \mathrm{g} / \mathrm{ml}$ of hygromycin.

\subsection{Western blot analysis}

After three weeks of incubation, bacterial cells were harvested by centrifugation, broken by disruption with glass beads in a homogenizer, and resuspended in PBS $1 \mathrm{X}$ for protein quantification. Secreted proteins were obtained from culture supernatants of bacteria grown in medium with $0.4 \%$ glucose but without albumin. The supernatants containing secreted proteins were precipitated with $10 \%$ trichloroacetic acid overnight and centrifuged at $7000 \mathrm{~g}$ for $30 \mathrm{~min}$ at $4{ }^{\circ} \mathrm{C}$. The proteins were neutralized with Tris $1 \mathrm{M}$ and resuspended in loading buffer.

The samples were subjected to electrophoresis in 12-15\% SDSPAGE gels, subsequently transferred to nitrocellulose membranes and stained with Rouge Ponceau solution. The membranes were blocked with TBS (10 mM tris $-\mathrm{HCl} \mathrm{pH} 7.5,150 \mathrm{mM} \mathrm{NaCl})$ supplemented with $5 \%$ skim milk for $30 \mathrm{~min}$ before performing an overnight incubation with primary antibodies (monoclonal anti-ESAT-6 (1/100) or polyclonal GroEL (1/5000). The nitrocellulose membranes were then incubated with a secondary antibody alkaline phosphatase-conjugated at a 1:10.000 dilution for $2 \mathrm{~h}$. Western blots were revealed by incubation with BCIP/NTP solution.

\section{Results and discussion}

\subsection{Comparative analysis of predicted proteins in M. bovis strains}

The comparison of SNPs of the 04-303 and 534 strains, through the evaluation of their genomes in relation to that of the M. bovis AF2122/ 97 reference strain, retrieved 193 genes with at least NS-SNP in one of the strains or in both (Supplementary material 1). In total, 57 genes carried NS-SNPs in 04-303, whereas 84 did it in 534. Interestingly, 53 of the NS-SNPs were common to both strains. From the exclusive NSmutations, nine produced a frameshift, whereas two resulted in premature stops in the proteins (Supplementary material 1).

A functional categorization (tuberculist.epfl.ch) of the polymorphic proteins between 04-303 and 534 showed that the most represented categories in mutant proteins of 534 are PE/PPE and intermediary metabolism and respiration. On the other hand, 04-303 carries NS-SNPs mainly in genes of the lipid metabolism category (Supplementary material 1). 
Intermediary metabolism and respiration

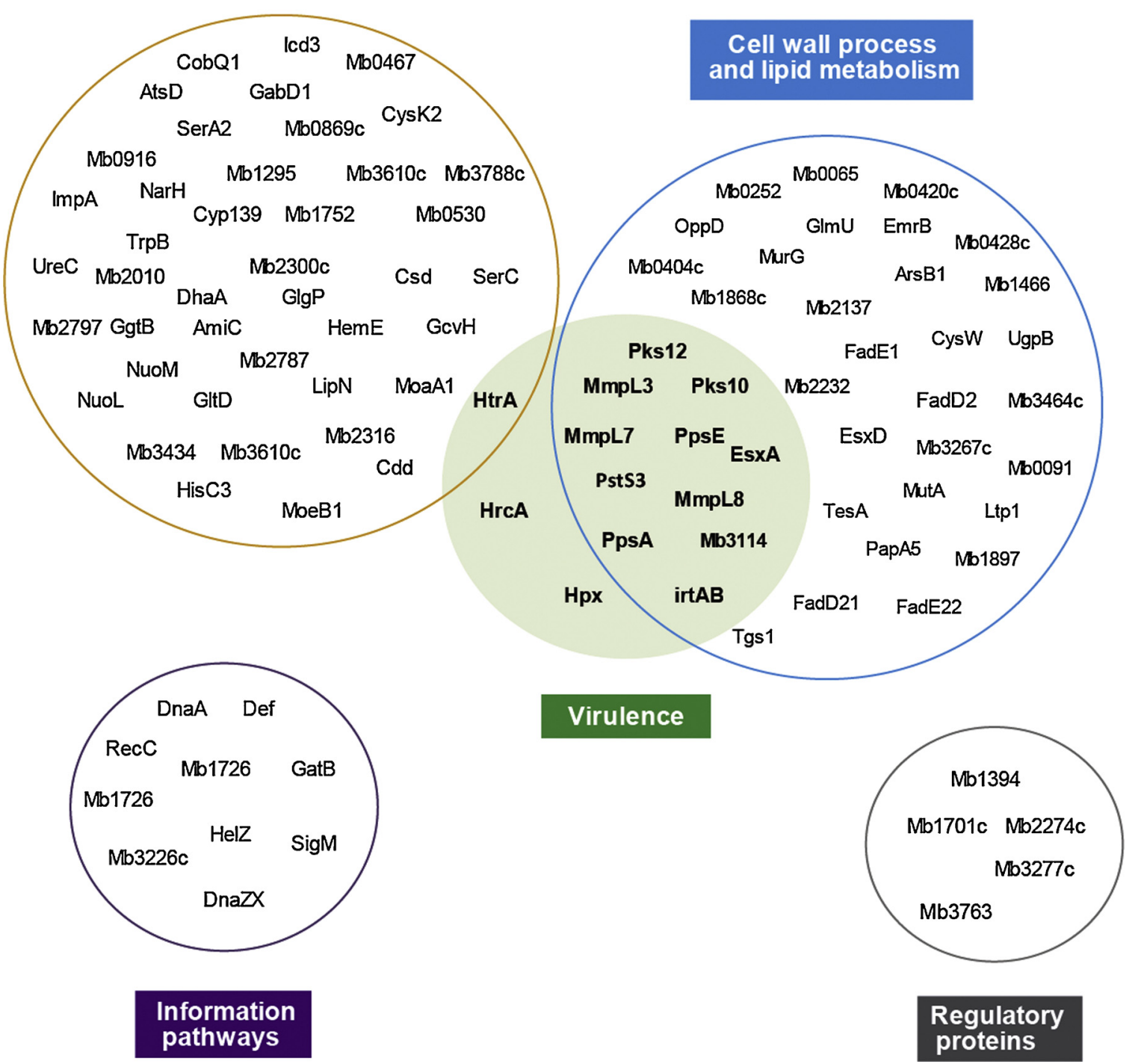

Fig. 1. Venn diagram illustrating polymorphic virulence genes of both 04-303 and 534 strains grouped as functional categories.

\subsection{Polymorphic virulence genes}

A search for virulence genes in the polymorphic gene dataset, based on the bibliography and on the Tuberculist functional categories, gave nine virulence genes with nonsynonymous polymorphisms in 04-303 and five in 534 . These 14 polymorphic genes with a putative or demonstrated role in mycobacteria virulence grouped in five functional categories: three genes are involved in cell wall process (esxA, pstS3 and irtAB); eight are associated with lipid metabolism ( $p k s 12, \mathrm{mmpL3}$, pks10, mmpL7, mmpL8, Mb3114, ppsA and $p p s E)$; one was involved in intermediary metabolism and respiration ( $h t r A)$; one encoded a regulatory protein $(h r c A)$ and one categorized as virulence gene $(h p X)$ (Fig. 1). These results highlight the relevance of the cell wall and related lipids in the mechanism of virulence of pathogenic mycobacteria.

Of the eight virulence polymorphic proteins involved in lipid metabolism, four are enzymes of phthioceroldimycocerosate (PDIM) synthesis/transport pathways, three are $\mathrm{MmpL}$ proteins involved in lipid transport and one is a putative glycerolphosphodiesterase (Mb3114) predicted to be required for in vivo survival of $M$. tuberculosis (Sassetti et al., 2003). The genes mmpL3, 7 and 8 have NS-SNPs in the
04-303 strain. The proteins of the MmpL family translocate complex lipids across the cell envelope of mycobacteria. MmpL8 transfers the sulfolipid SL-1 to the cell envelope (Converse et al., 2003) and MmpL7 transports PDIM. A study demonstrated that the lack of MmpL7 in $M$. tuberculosis severely affects the virulence of the bacteria, whereas the absence of MmpL8 attenuates it (Domenech et al., 2005). MmpL 7 and 8 of 04-303 showed aa changes that predictably favours its stability (Table 1). Therefore, if mutations in MmpL proteins have an impact on the virulence of 04-303, they should favour the protein functionality. MmpL3 (Mb0212) transports trehalose momomycolate, a precursor of the mycobacterial outer membrane component trehalose dimycolate as well as mycolic acids bound to arabinogalactan. However, since this gene is essential for bacterium replication in vitro, it is difficult to speculate about the role of the mmpL3 mutation in the virulence phenotype of 04-303. In addition, the mutation seems to not affect the lipid transportation function, since we did not detect substantial differences in the content of TDM or extractable mycolic acids between strains (Supplementary material 2A and 2B).

The PDIM lipids consist of a long-chain $\beta$-diol - phthiocerol - esterified by one type of such long-chain multiple methyl-branched fatty 
Table 1

Polymorphic virulence proteins in $M$. bovis strains compared to M. bovis AF2122/97.

\begin{tabular}{|c|c|c|c|c|c|c|c|c|c|c|}
\hline $\mathrm{Mb}$ number & Name & Rv number & Description & Length & Location & $\mathrm{aa}^{\mathrm{Mb}}$ & $\mathrm{aa}^{\mathrm{Rv}}$ & Change & ddG & $\% \S$ \\
\hline & \multicolumn{10}{|c|}{ M. bovis strain 04-303 } \\
\hline Mb0212c & MmpL3 & Rv0206c & Transport protein $\mathrm{Mmpl} 3$ & 944 & 820 & A & A & $\mathrm{P}$ & ND & 3.1 \\
\hline Mb0951 & PstS3 & Rv0928 & Periplasmic phosphate-binding lipoprotein & 370 & 84 & $\mathrm{~N}$ & $\mathrm{~N}$ & $S$ & -1.37 & 3.1 \\
\hline Mb2074c & Pks12 & Rv2048c & Polyketide synthase Pks12 & 4151 & 3971 & $\mathrm{~S}$ & $\mathrm{~S}$ & Fs & ND & 9.4 \\
\hline Mb2395c & HrcA & Rv2374c & Probable heat shock protein transcriptional repressor & 343 & 78 & $\mathrm{D}$ & $\mathrm{D}$ & $\mathrm{N}$ & +1.6 & 3.1 \\
\hline Mb2967 & MmpL7 & Rv2942 & Transport protein Mmpl7 & 920 & 407 & $\mathrm{I}$ & $\mathrm{I}$ & $\mathrm{T}$ & +2.5 & 3.1 \\
\hline Mb3114 & Rv3087 & Rv3087 & Possible triacylglycerol synthase & 472 & 453 & $\mathrm{~S}$ & $\mathrm{~S}$ & $\mathrm{~L}$ & ND & 3.1 \\
\hline Mb3196c & Hpx & Rv3171c & Possible non-heme haloperoxidase & 299 & 7 & $\mathrm{D}$ & $\mathrm{D}$ & G & ND & 3.1 \\
\hline Mb3853c & MmpL8 & Rv3823c & Transport protein $\mathrm{Mmpl8}$ & 1089 & 451 & $\mathrm{~L}$ & $\mathrm{~L}$ & $\mathrm{~V}$ & +4.93 & 3.1 \\
\hline \multirow[t]{2}{*}{ Mb3905 } & EsxA & Rv3875 & $6 \mathrm{kda}$ early secretory antigenic target esxa (esat-6) & 95 & 63 & $\mathrm{~T}$ & $\mathrm{~T}$ & A & +0.52 & 3.1 \\
\hline & \multicolumn{10}{|c|}{ M. bovis strain 534} \\
\hline Mb1255 & HtrA & Rv1223 & Serine protease htra (degp protein) & 528 & 272 & I & I & M & -0.08 & 18.8 \\
\hline Mb1383 & IrtA & Rv1348 & Atp-binding protein Abc transporter & 859 & 562 & $\mathrm{R}$ & $\mathrm{R}$ & $\mathrm{L}$ & +2.35 & 9.4 \\
\hline Mb1688 & Pks10 & Rv1660 & Chalcone synthase Polyketide synthase Pks10 & 353 & 330 & $\mathrm{~S}$ & $\mathrm{~S}$ & G & ND & 2.6 \\
\hline Mb2074c & Pks12 & Rv2048c & Polyketide synthase Pks12 & 4151 & 3982 & $\mathrm{H}$ & $\mathrm{Q}$ & $\mathrm{Q}$ & ND & 6.3 \\
\hline Mb2074c & Pks12 & Rv2048c & Polyketide synthase Pks12 & 4151 & 3985 & $\mathrm{H}$ & $\mathrm{E}$ & $\mathrm{E}$ & ND & 3.1 \\
\hline Mb2956 & PpsA & Rv2931 & Polyketide synthase PpsA & 1876 & 1809 & $\mathrm{~F}$ & $\mathrm{~F}$ & $\mathrm{~L}$ & +0.17 & 15.6 \\
\hline Mb2960 & PpsE & Rv2935 & Polyketide synthase PpsE & 1488 & 538 & G & G & $\mathrm{S}$ & +4.92 & 18.8 \\
\hline
\end{tabular}

$\S$ frequency of NS-mutation in $M$. bovis isolates.

aa ${ }^{\mathrm{Mb}}$ Amino acid in $M$. bovis AF2122/97 strain.

aa ${ }^{\mathrm{Rv}}$ Amino acid in M. tuberculosis H37Rv strain.

acids called mycocerosic acids. PDIMs constitute major virulence factors of $M$. tuberculosis, particularly, during the early step of infection when bacilli encounter their host macrophages. Two transcriptional units are involved in the synthesis and transport of PDIMs. These transcriptional units contain many genes involved in fatty acid synthesis/modification, many of them with homology to fatty acyl CoA synthases and dehydrogenases, as well as a set of genes with homology to polyketide synthases ( $\mathrm{Pks}$ ). Pks are multifunctional enzymes that, along with adjacent or neighbouring Acyl-CoA synthases and dehydrogenases could be involved in the synthesis of complex lipids such as mycocerosic acid, sulfolipids, diacyltrehalose/polyacyltrehalose (DAT/ PAT). Mutants in pks12 and pks10 genes of M. tuberculosis displayed defect in PDIM production (Sirakova et al., 2003). However, later studies demonstrated that Pks12 is involved in the synthesis of Mannosylbeta -1-phosphomycoketides (MPM) (Angala et al., 2014). Therefore, at least for Pks12, the role of this enzyme in the accumulation of PDIM seems to be secondary or indirect.

Pk10 showed polymorphisms only in the 534 strain, whereas Pks12 was polymorphic in both strains. A single nucleotide deletion in the coding sequence of $\mathrm{Pks} 12$ produced a frameshift in the resulting protein of the 04-303 strain, whereas a double amino-acid (aa) substitution occurred at the $\mathrm{C}$ terminal end (QxH and ExH) of Pks12 in 534. Moreover, PpsA and PpsE, which are also polyketide synthases encoded in one of the PDIM loci (Domenech and Reed, 2009), showed NS-mutations in the 534 strain. Although predictive analysis indicates that these mutations are supposed to produce stability to the resulting protein structures (Table 1), they map in conserved domains, according to ScanProsite (data not shown). Therefore, the enzymatic activities of PpsA and PpsE may be affected.

Altogether, this genomic analysis shows a remarkable high level of polymorphism in proteins related to PDIM synthesis or transport in both strains.

The comparative genomic analysis identified only one NS-mutation in a regulatory gene of 04-303 and none in 534. The identified polymorphic regulatory gene is $h r c A(M b 1255)$. HrcA is a heat-shock protein that acts as a transcriptional repressor for members involved in the Hsp60 (GroEL) response to M. tuberculosis (Stewart et al., 2002). The mutation of HrcA in 04-303 produced an aa change from aspartate, a negatively polar side-chain aa, to asparagine, an uncharged polar side chain aa. This aa change should destabilize the protein structure as predicted by STRUM (Table 1). A western blot analysis showed no differences in the expression of the GroEL protein (Supplementary material 2D), suggesting no alteration in the expression level because of this aa change in HrcA.

In this study, we detected NS-mutations in four membrane/cell wall associated genes: irtA, pstS3, $h p X$ and $h t r A$. IrtA together with IrtB are proteins involved in iron acquisition. Here, we identified a change of a leucine, an uncharged polar side chain aa, to an arginine in the protein sequence of IrtA in the 534 strain. The mutation maps in a conserved domain detected by ScanProsite tool (data not shown).

PstS-3 is a protein involved in the transport of inorganic phosphate together with PhoT. Previous results indicate that PstS-3 may have a minor role in the virulence mechanisms of $M$. tuberculosis (Brodin et al., 2010). In the 04-303 strain, pstS-3 carries a NS-SNP that is predicted to produce a negative stability change in the resulting protein (Table 1). This suggests that the mutation does not contribute to the virulence phenotype of the $M$. bovis strain.

Hpx carries a NS-mutation in the 04-303 strain. This gene encodes a putative non-heme haloperoxidase identified in the cell membrane of M. tuberculosis (Mawuenyega et al., 2005) that may be involved in detoxification reactions. No experimental characterization has been done so far and therefore its role in $M$. bovis virulence is still undefined.

HtrA-1 (DegP) is a member of the serine protease family. This protein is essential, as determined by saturation transposon mutagenesis and through attempts to knock-out the gene (Roberts et al., 2013) (Sassetti et al., 2003). The essentiality of htrA-1 indicates that its NSmutation in the 534 strain should not affect the protein functionality, although the mutation predictively affects the protein stability.

Only the $6 \mathrm{kDa}$ early secretory antigenic target (ESAT-6) or EsxA, which is a secreted virulence factor, showed polymorphism between the strains. ESAT-6 is a highly conserved protein (Encinas et al., 2018) that is part of a protein family known as Esx. ESAT-6 of M. bovis forms a dimer with CFP10 (culture filtrate antigen or EsxB) (Mb3904), a strong stimulator of cell-mediated immunity (Jones et al., 2010). ESAT6:CFP10 can sequester the host protein beta-2-microglobulin (b2M) to inhibit the cell surface expression of the major histocompatibility complex (MHC)-I-b2M; which may undermine the host's adaptive immune responses, thereby leading to the establishment of a successful infection (Sreejit et al., 2014).

Indeed, the 04-303 strain showed a NS-SNP in esat- 6 that improves the stability of the protein, as predicted by STRUM analysis (Table 1). Furthermore, this NS-SNP does not affect the secretion of the protein, as 

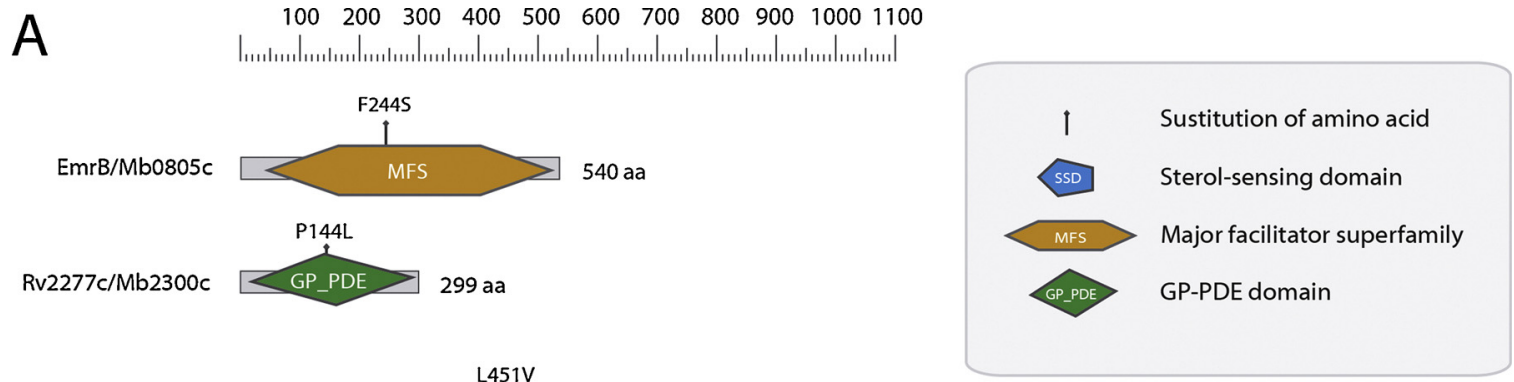

MmpL8/Mb3853c

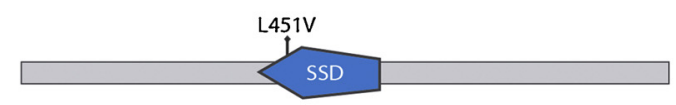

1089 aа

B

$100 \quad 200 \quad 300 \quad 400 \quad 500 \quad 600 \quad 700 \quad 800900 \quad 1000$

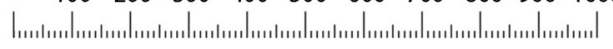

irtAB/Mb1383

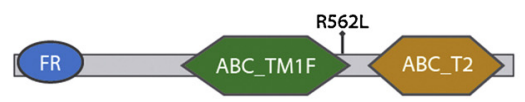

859 aa

Rv1461/Mb1496

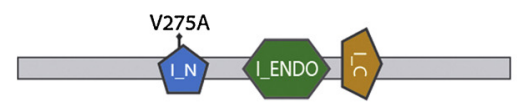

846 aa

$\mathrm{Rv} 2250 \mathrm{c} / \mathrm{Mb} 2274 \mathrm{c}$

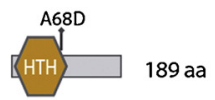

Rv3239c/Mb3267c
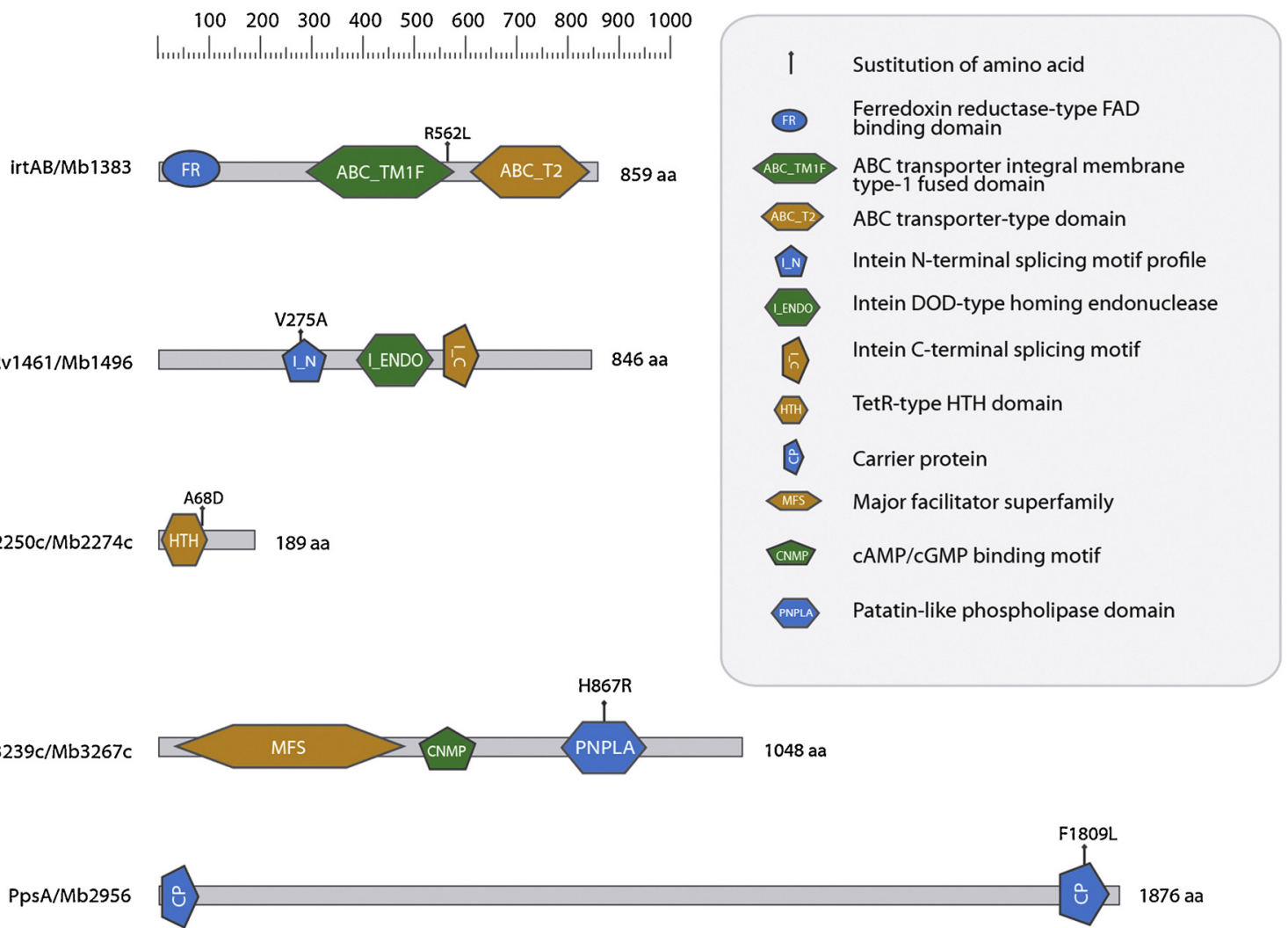

Fig. 2. Schematic representation of polymorphisms in protein conserved domains of (A) 04-303 and (B) 534 strains. Only domains identified by both ScanProsite and CD search were considered in this study.

evidenced by the equivalent amounts of ESAT- 6 expression in the culture supernatants of both strains (Supplementary material 2D).

\subsection{Polymorphism in conserved protein domains}

Five polymorphisms map in conserved predicted domains (Fig. 2). The 04-303 strain has a polymorphism in the major facilitator superfamily (MFS) and glycerophosphodiester phosphodiesterase (GP-PDE) domain of Mb0805c and Mb2300c, respectively. Mb0805c is a putative multidrug resistance integral membrane efflux protein (Emrb), whereas $\mathrm{Mb} 2300 \mathrm{c}$ is a putative glycerolphosphodiesterase. For both proteins, the predictive domains encompass more than $89 \%$ of the full protein length (Fig. 2A) and, therefore, it is difficult to assign an impact for the aa changes.

In the 534 strain, Mb1496c and Mb3267c are conserved hypothetical protein with an aa change in an intein $\mathrm{N}$-terminal splicing and a patatin-like phospholipase (PNPLA) domains, respectively (Fig. 2B). In addition, $\mathrm{Mb} 2274 \mathrm{c}$ is a putative transcriptional regulatory protein that carries a predictive aa change in a TetR-type HTH domain. All of these conserved domains that showed polymorphisms in the 534 strain in relation to the $M$. bovis reference strain are in proteins with no established functions in mycobacteria. However, Mb2274c has been assigned a predictive transcriptional regulation function (http://genolist. pasteur.fr/BoviList/). Thus, the mutation in its HTH domain may have an impact on the binding of the protein to the DNA, which in turn would affect the transcriptional expression of the target genes.

\subsection{Frameshift mutations}

Rv1264 (Mb1295) is one of the 15 adenylyl cyclases of $M$. tuberculosis that produce cAMP (Findeisen et al., 2007). This enzyme is activated at acidic $\mathrm{pH}$ due to $\mathrm{pH}$-dependent structural transitions of the 
Table 2

Frameshift mutations in $M$. bovis strains compared to M. bovis AF2122/97.

\begin{tabular}{|c|c|c|c|c|c|}
\hline Mb number & Name & Rv number & Description & Length & Location of Fs \\
\hline \multicolumn{6}{|l|}{ 04-303 } \\
\hline Mb3920c & EsxD & Rv3891c & Esat-6 like protein esxd & 107 & 40 \\
\hline \multicolumn{6}{|l|}{534} \\
\hline Mb1246c & PE14 & Rv1214c & Pe family protein & 376 & $69 *$ \\
\hline Mb1295 & - & Rv1264 & Adenylyl cyclase & 397 & 371 \\
\hline $\mathrm{Mb} 2437 \mathrm{c}$ & - & Rv2414c & Conserved hypothetical protein & 523 & 58 \\
\hline $\mathrm{Mb} 2813 \mathrm{c}$ & Ltp1 & Rv2790c & Probable lipid & 401 & 6 \\
\hline Mb3370 & - & Rv3338 & conserved hypothetical protein & 297 & 83 \\
\hline Mb3610c & - & Rv3579c & Possible trna/rrna methyltransferase & 403 & 317 \\
\hline
\end{tabular}

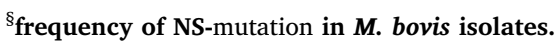

*insertion of 5'ACAAG.3'

Rv1264 dimer. In the 534 strain, a frameshift mutation in Mb1295 produced a predictive larger protein than that of the wild type (410 vs 397 aa). However, the mutated region is located at the end of the carboxyl terminal domain of the protein and does not encompass conserved domains or a conserved aa.

A single nucleotide deletion in $M b 2813$ of 534 results in a predictable protein of only 17 aa. $M b 2813$ encodes a putative lipid-transfer protein Ltp1 (Table 2). The role of this protein during tuberculosis infection remains unknown. Based on the relevance of the mycobacterial lipids for the interaction with their host, it is tempting to speculate that the lack of this putative lipid transfer protein may impact on the virulence of the strain 534 .

Other frameshift mutations in the 534 strain are those located in $M b 2437 c$ and $M b 3370$, which produced truncated proteins of 133 and 150 aa, respectively (Table 2). These aberrant proteins would conserve only 56 and 83 aa of the amino terminal portion of the wild type proteins, respectively. These genes encode hypothetical proteins not previously described in the literature.

PE family protein PE14 (Mb1246c) of 534 carries a five nucleotides insertion that results in a shorter protein of 69 aa in relation to the reference strain. Although the function of this protein is still unknown, this five nucleotides insertion is also present in M. tuberculosis H37Rv reference strain but in different position. The insertion localizes at nucleotide position 205 from $5^{\prime}$ end of $M b 1246 c$ and nucleotide position 204 from 5' end of $R v 1214 c$.

A mutation that maps at the end of $M b 3610$ in the 534 strain produces a predictable protein 81 aa shorter than that of the wild type (Table 2). Mb3610, a putative tRNA/rRNAmethyltransferase, seems to be essential for $M$. tuberculosis growth and, thus, any mutation detected in this gene should have no impact on the functionality of the protein.

Only two frameshift mutations were exclusively identified in the 04303 strain (Table 2). One is in the pks12 gene, previously mentioned, and the other maps in the Mb3920c gene. Mb3920c (EsxD) is a member of the ESAT- 6 family that, together with Mb3919c (EsxC), may be secreted by the ESX-2 system (Knudsen et al., 2014). Nevertheless, EsxD and EsxC lack the ESX signature tag. None of these proteins have been identified in the culture supernatants. The deletion of a single nucleotide from $M b 3902 c$ in the 04-303 strain would produce a protein of 63 aa, of which only the first 40 are identical to the wild type protein. The dimmer EsxC/EsxD formulated in adjuvant CAF01 has shown to confer a significant level of protection against $M$. tuberculosis in a mouse model (Knudsen et al., 2014). This finding may suggest that the lack of a fulllength EsxD would facilitate 04-303 to evade the host immune response.

\subsection{Polymorphisms in other M. bovis isolates}

We extended the analysis of the selected polymorphic proteins to other $30 \mathrm{M}$. bovis genomes obtained from the public database (https:// www.ncbi.nlm.nih.gov/gquery/). In the 04-303 strain, most of the NS- mutations in the selected genes are unique. The exceptions are in the case of pks12 (Table 1), which encodes a protein highly polymorphic among M. bovis strains, and $M b 2300 c$ (Rv2300c) which showed the same polymorphism in $96.9 \%$ of the analysed $M$. bovis isolates (data not shown) This unexpected finding may explain the exacerbated virulence of 04-303 (Meikle et al., 2011).

The frequency of mutations is contrasting in the 534 strain, where most of NS-SNPs are present in other M. bovis isolates. Based on the premise that evolutionary forces would not select mutations that have a negative impact on the virulence of $M$. bovis, we should conclude that most of the mutations in the 534 strain are not associated with its attenuation. The exceptions are pks10, the adenylyl cyclases Mb1295 (Rv1264) and Mb1496 (Rv1461) (Table 1 and data not shown), which have unique mutations. In addition, for $h r t A$, only another strain shares this NS-mutation with $M$. bovis 534 . In the case of these genes, the mutations would be effectively associated with a disadvantage for infection.

\subsection{Comparative lipid analysis}

Based on the high number of lipid-related proteins with polymorphisms between strains, we decided to compare the lipid content of these bacteria. Preparation and TLC analysis of total lipids from the cellular extractable lipids showed that some lipids were exclusively present in the 04-303 strain (Fig. 3A). When total lipids prepared from cell extracts were solved in a solvent system that resolved PDIM, we detected the accumulation of multiple bands in 04-303, which were absent from the 534 strain (Fig. 3B). To determine whether these differences in PDIM profiles between strains were a consequence of bacterial sub-culturing, we analysed the PDIM content of bacterial cells obtained from seed stocks (original cultures with minimal passages). The lipid profiles were similar to those of Fig. 3B (Supplementary material 2C). This result indicates that the lower content of PDIM in the 534 strain was not due to the mutations in PDIM-related genes accumulated during in vitro bacterial culturing. These phenotypes, which were reproducible throughout five independent experiments, suggest that the NS-mutations either in $p k 10$, ppsA, ppsE or altogether dramatically impact on the PDIM production of 534.

In addition, the differences in lipid content were confirmed by an LC-MS analysis of the cellular extractable lipids from both strains (Fig. 3C, D and E). Mass spectra clearly showed an increase in the peaks eluting between 22.5 and 26.5 min that matched with mycoside B, a lipid that shares much of the biosynthetic pathways of PDIM, PDIMA and PDIMB in samples from the 04-303 strain. The higher accumulation of PDIMs in the 04-303 strain than in the 534 strain was confirmed in a second LC-MS analysis with a set of lipid samples obtained from seed stocks (data not shown). Altogether, the production of PDIMs showed to be altered in 534 strain. 

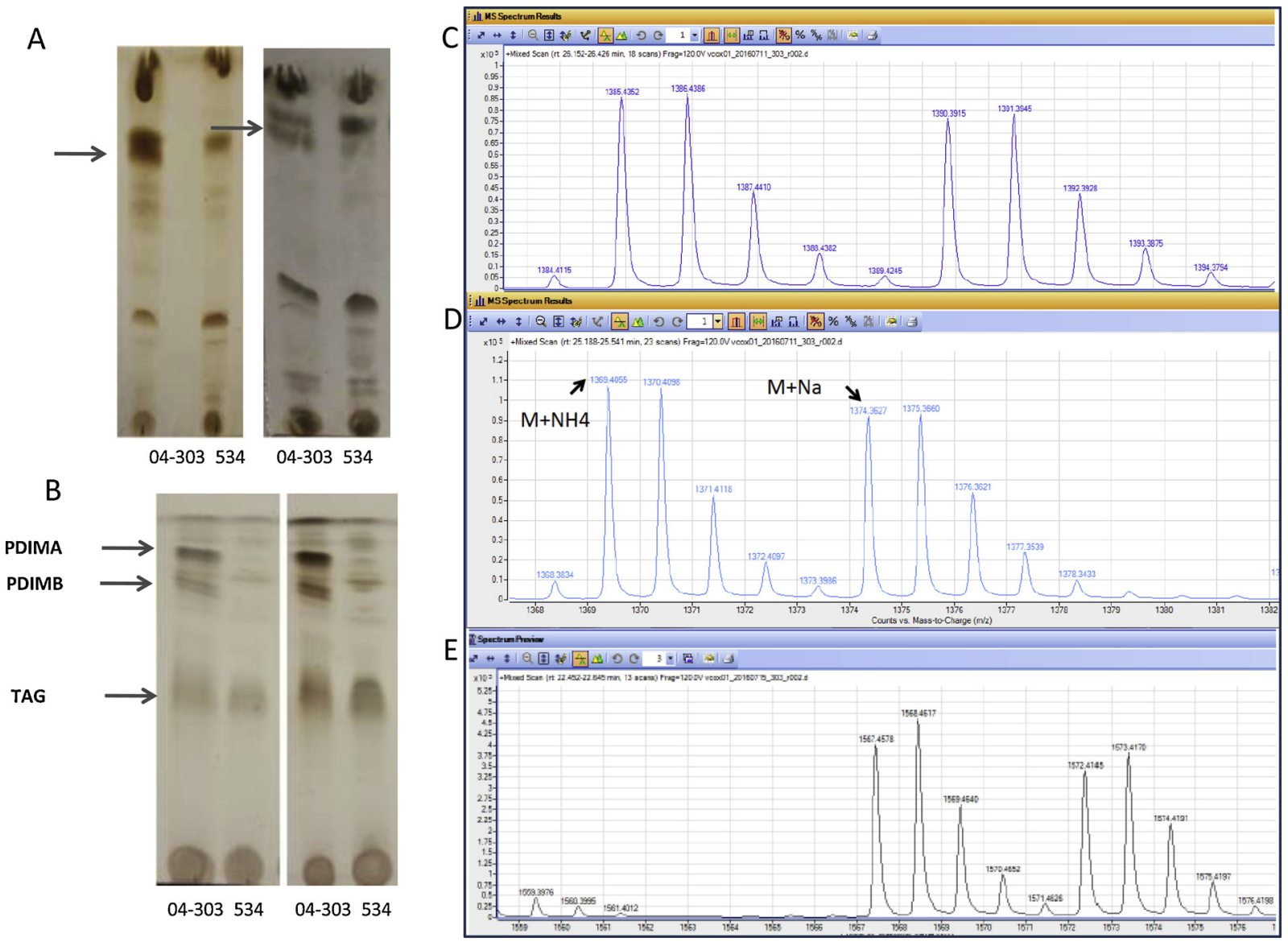

Fig. 3. Lipidomic analysis. (A, B) Thin layer chromatography analysis of total lipid from $M$. bovis strains. Total lipids were extracted from $M$. bovis strains developed by TLC in the solvent systems (A) chloroform methanol water (90:10:1) (B) petroleum ether/diethyl ether (98:2) and revealed with CuSO4 and heating. The arrows indicate increased lipids in 04-303. The lipid patterns were repeated in five independent experiments. (C, D, E) LC-MS analysis of total lipids from M. bovis strains. (C) The TIC and the selection ion chromatograms at $m / z 1322.314(\mathrm{M}+\mathrm{Na}+$ for DIMB) and at $m / z 1530.382(\mathrm{M}+\mathrm{Na}+$ for a DIMA based mycoside B) for total lipid extracts from 04-303 and 534 strains. Consistent with the TLC analysis, both strains show large amounts of various forms of triglycerides (labelled on the TLC of Fig. 3). Strain 04-303 also shows substantial amounts of various forms of both mycoside B and DIM (also labelled on the TLC of Fig. 3). The selected ion chromatograms show that both DIM and mycoside B are present in the 04-303 strain; integration shows the ratio at approximately 75:1 (303:534) for both lipids. DIMA and mycoside B based on DIMB were also present in the 04-303 strain in substantial amounts (data not shown). The mass spectrum of the major DIMB is shown in (D); the structural drawing, while correct in its molecular weight, is not necessarily accurate as to which $\mathrm{CH} 2$ groups are in the fatty acids and which are on the main chain of the phthiocerol backbone. Similarly, the mass spectrum of the major mycoside B based on DIMA is shown (E) and, although the phthiocerol backbone and the acyl groups are clearly smaller than those of the DIMs, the drawing is not necessarily accurate as to which $\mathrm{CH} 2$ groups are in the fatty acids and which are on the main chain of the phthiocerol backbone.

\subsection{Intracellular trafficking of $M$. bovis strains}

ESAT-6 in concert with other proteins and PDIM lipids contribute to the phagosomal escape of M. tuberculosis (Augenstreich et al., 2017). Thus, the variable abundance of PDIM between the 04-303 and 534 strains and the polymorphism in ESAT- 6 may have an impact on intracellular localization of both strains. To address this point, we evaluated the maturation stage of mycobacterial phagosomes by using immunofluorescence and confocal microscopy.

$M$. bovis strains were used to infect bovine macrophages for $2 \mathrm{~h}$ of uptake and $72 \mathrm{~h}$ of chase, as described in Materials and Methods. Consistent with our presumption, the LAMP-3 (the late endocytic marker lysosomal-associated membrane protein 3) association with the 04-303 was significantly lower than with the 534 strain (Fig. 4B). These results indicate that the 534 strain has a reduced ability to avoid antimicrobial mechanisms of macrophages and therefore it cannot persist inside bovine macrophages. As expected, the number of CFU in macrophages infected with strain 04-303 was significantly higher than that of macrophages infected with either strain 534 or BCG at $72 \mathrm{~h}$ of infection (Fig. 4A). These results are in line with our previous findings (Blanco et al., 2009).
To evaluate the impact of ESAT-6 polymorphism on the intracellular persistence of $M$. bovis, we overexpressed the mutant (ESAT-6- 04-303) and wild type (ESAT-6-534) variants of ESAT- 6 in the 534 strain from plasmid pVV16. The introduction of the mutant allele of esat- 6 in 534 did not affect the intracellular localization of the strain in late endosomes (Supplementary material 2E-i). This result suggests that the mutation of ESAT- 6 does not improve the phagosomal escape of pathogenic mycobacteria. In addition, we detected equivalent intracellular persistence of both recombinant 534 strains at 48 and $72 \mathrm{~h}$ post infection of bovine macrophages (Supplementary material 2E-ii). Altogether these results indicate that, at least with the ex vivo model here evaluated, the mutation in ESAT- 6 does not seem to contribute to exacerbate the virulence phenotype of strain 04-303.

\section{Conclusions}

In this study, we used a genomic approach to predict the molecular bases that can explain the extreme opposite phenotypes in terms of virulence of two genetically close $M$. bovis strains. Most of the NS-mutations in virulence factors mapped in proteins related to transport or metabolism of lipids. This finding reinforces the role of these 
$\mathbf{A}$

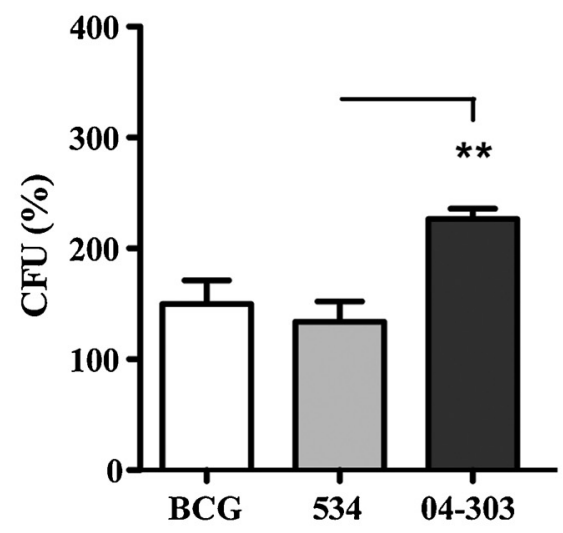

B-i
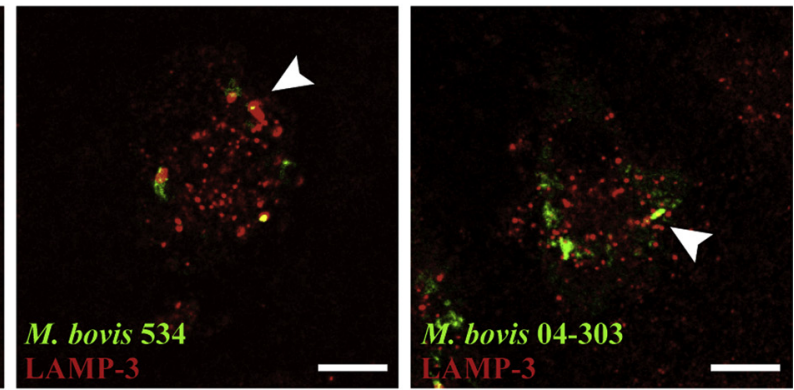

Fig. 4. Intracellular trafficking of $M$. bovis strains in bovine macrophages. The PBMC-derived bovine macrophages were infected with the different $M$. bovis strains for $2 \mathrm{~h}$ of uptake and $72 \mathrm{~h}$ of chase. (A) Intracellular survival of $M$. bovis strains in bovine macrophages. Macrophages were infected with $M$. bovis strains at MOI: 2. Colony forming units were counted $3 \mathrm{~h}$ post infection (to study inoculum possible variations between strains) and at $72 \mathrm{~h}$ (**) $\mathrm{p} \leq 0.01$ ANOVA with Bonferroni post test. (B) Cells were fixed, subjected to indirect immunofluorescence using an antibody against Mycobacterium (green) and an antibody against LAMP-3 (red). Then cells were analysed by confocal microscopy (B-i). The head arrows in merge images show the mycobacterial phagosomes. Scale bars: $10 \mu \mathrm{m}$. (B-ii) Quantitation of LAMP-3 associated with the different $M$. bovis strain phagosomes. Data represent the Mean \pm S.E.M. of three independent experiments. Asterisks show significance (***) $\left.\mathrm{p} \leq 0.001,{ }^{* *}\right) \mathrm{p} \leq 0.01$ and ns: no significative. More than 500 phagosomes were analysed. The data were analysed using twotailed Student's t-test and one-way ANOVA with Tukey's post hoc test (For interpretation of the references to colour in this figure legend, the reader is referred to the web version of this article).

\section{B-ii}

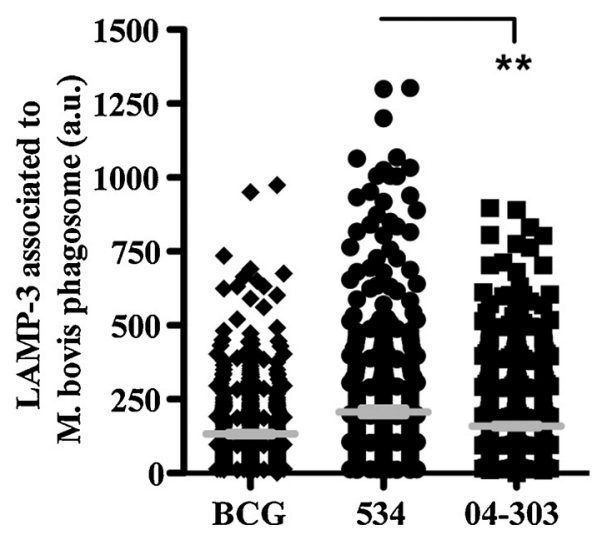

compounds in the virulence of pathogenic mycobacteria. While most of the mutations in virulence proteins of 534 strain are conserved in a high number of $M$. bovis isolates, mutations in virulence proteins of 04-303 are mostly unique Thus, the 04-303 protein polymorphisms may contribute to the high virulence of this strain. However, experimental evidence is necessary to confirm this presumption.

Although we detected several proteins with significant changes between strains, such as premature stop, frameshift mutations and aa changes in conserved domains, the high number of NS-polymorphisms in enzymes that participate in PDIM metabolism in both strains is remarkable. This predictive analysis was then confirmed with experimental results and thus we demonstrated that the 534 strain has a dramatic defect in PDIM production. The lack of PDIM and the related lipids in the attenuated strain 534 is consistent with the role of these lipids in the virulence of $M$. tuberculosis and M. bovis.

\section{Funding statement}

This work was funded by ANCyPT Grant PICT2018 01113 INTA Grant I105 and I102; CONICET 11220130100225CO and Res. 2322/15; 
Embrapa 02.13.10.008.00.00, CNPq 443235/2014-7, FUNDECT 085/ 2015. The funders had no role in study design, data collection and analysis, decision to publish, or preparation of the manuscript.

\section{Declarations of Competing Interest}

None.

\section{Acknowledgements}

We are grateful to Dr Julia Sabio for critical reading of this paper. We thank Valeria Rocha (INTA) and Victoria Cox-Jones (CSU) for her valuable technical help. We also thank Cecilia Marquez and Analítica S.A. for helping us with LS-MS data with MassHunter software and Mercedes Gonzales -Juarrero (CSU) for her help in confocal study. F. Bigi, M. Zumárraga, A. Cataldi are CONICET fellows. Bei Resources (TBVRM, Colorado State University) kindly provided pVV16 plasmid, Anti- ESAT-6 and GroEL antibodies.

\section{Appendix A. Supplementary data}

Supplementary material related to this article can be found, in the online version, at doi:https://doi.org/10.1016/j.vetmic.2019.108482.

\section{References}

Aguilar León, D., Zumárraga, M.J., Jiménez Oropeza, R., Gioffré, A.K., Bernardelli, A., Orozco Estévez, H., Cataldi, A.A., Hernández Pando, R., 2009. Mycobacterium bovis with different genotypes and from different hosts induce dissimilar immunopathological lesions in a mouse model of tuberculosis. Clin. Exp. Immunol. 157, 139-147. https://doi.org/10.1111/j.1365-2249.2009.03923.x.

Alexander, K.A., Laver, P.N., Michel, A.L., Williams, M., van Helden, P.D., Warren, R.M., van Pittius, N.C.G., 2010. Novel mycobacterium tuberculosis complex pathogen, M. Mungi. Emerg. Infect. Dis. 16, 1296-1299. https://doi.org/10.3201/eid1608. 100314.

Angala, S.K., Belardinelli, J.M., Huc-Claustre, E., Wheat, W.H., Jackson, M., 2014. The cell envelope glycoconjugates of Mycobacterium tuberculosis. Crit. Rev. Biochem. Mol. Biol. 49, 361-399. https://doi.org/10.3109/10409238.2014.925420.

Augenstreich, J., Arbues, A., Simeone, R., Haanappel, E., Wegener, A., Sayes, F., Le Chevalier, F., Chalut, C., Malaga, W., Guilhot, C., Brosch, R., Astarie-Dequeker, C., 2017. ESX-1 and phthiocerol dimycocerosates of Mycobacterium tuberculosis act in concert to cause phagosomal rupture and host cell apoptosis. Cell. Microbiol. 19. https://doi.org/10.1111/cmi.12726.

Blanco, F.C., Nunez-García, J., García-Pelayo, C., Soria, M., Bianco, M.V., Zumárraga, M., Golby, P., Cataldi, A.A., Gordon, S.V., Bigi, F., 2009. Differential transcriptome profiles of attenuated and hypervirulent strains of Mycobacterium bovis. Microbes Infect. 11, 956-963. https://doi.org/10.1016/j.micinf.2009.06.006.

Brodin, P., Poquet, Y., Levillain, F., Peguillet, I., Larrouy-Maumus, G., Gilleron, M., Ewann, F., Christophe, T., Fenistein, D., Jang, J., Jang, M.S., Park, S.J., Rauzier, J., Carralot, J.P., Shrimpton, R., Genovesio, A., Gonzalo-Asensio, J.A., Puzo, G., Martin, C., Brosch, R., Stewart, G.R., Gicquel, B., Neyrolles, O., 2010. High content phenotypic cell-based visual screen identifies Mycobacterium tuberculosis acyltrehalosecontaining glycolipids involved in phagosome remodeling. PLoS Pathog. 6. https:// doi.org/10.1371/journal.ppat.1001100.

Brosch, R., Gordon, S.V., Marmiesse, M., Brodin, P., Buchrieser, C., Eiglmeier, K., Garnier, T., Gutierrez, C., Hewinson, G., Kremer, K., Parsons, L.M., Pym, A.S., Samper, S., van Soolingen, D., Cole, S.T., 2002. A new evolutionary scenario for the Mycobacterium tuberculosis complex. Proc. Natl. Acad. Sci. U. S. A. 99, 3684-3689. https://doi.org/ 10.1073/pnas.052548299.

Cole, S.T., Brosch, R., Parkhill, J., Garnier, T., Churcher, C., Harris, D., Gordon, S.V. Eiglmeier, K., Gas, S., Barry, C.E., Tekaia, F., Badcock, K., Basham, D., Brown, D. Chillingworth, T., Connor, R., Davies, R., Devlin, K., Feltwell, T., Gentles, S., Hamlin, N., Holroyd, S., Hornsby, T., Jagels, K., Krogh, A., McLean, J., Moule, S., Murphy, L., Oliver, K., Osborne, J., Quail, M.A., Rajandream, M.A., Rogers, J., Rutter, S., Seeger, K., Skelton, J., Squares, R., Squares, S., Sulston, J.E., Taylor, K., Whitehead, S., Barrell, B.G., 1998. Deciphering the biology of Mycobacterium tuberculosis from the complete genome sequence. Nature 393, 537-544. https://doi.org/10.1038/31159.

Converse, S.E., Mougous, J.D., Leavell, M.D., Leary, J.A., Bertozzi, C.R., Cox, J.S., 2003. MmpL8 is required for sulfolipid-1 biosynthesis and Mycobacterium tuberculosis virulence. Proc. Natl. Acad. Sci. U. S. A. 100, 6121-6126. https://doi.org/10.1073/ pnas. 1030024100

Domenech, P., Reed, M.B., 2009. Rapid and spontaneous loss of phthiocerol dimycocerosate (PDIM) from Mycobacterium tuberculosis grown in vitro: Implications for virulence studies. Microbiology 155, 3532-3543. https://doi.org/10.1099/mic.0. 029199-0.

Domenech, P., Reed, M.B., Barry, C.E., 2005. Contribution of the Mycobacterium tuberculosis MmpL protein family to virulence and drug resistance. Infect. Immun. 73, 3492-3501. https://doi.org/10.1128/IAI.73.6.3492-3501.2005.
Encinas, M., Marfil, M.J., Garbaccio, S., Barandiaran, S., Huertas, P., Morsella, C., Macías, A., Magnano, G., Zapata, L., Bigi, F., Cataldi, A., Paolicchi, F., Zumárraga, M., Eirin, M.E., 2018. Mycobacterium bovis ESAT-6, CFP-10 and EspC antigens show high conservation among field isolates. Tuberculosis 111, 143-146. https://doi.org/10. 1016/j.tube.2018.06.007.

Findeisen, F., Linder, J.U., Schultz, A., Schultz, J.E., Brügger, B., Wieland, F., Sinning, I., Tews, I., 2007. The structure of the regulatory domain of the adenylyl cyclase Rv1264 from Mycobacterium tuberculosis with bound oleic acid. J. Mol. Biol. 369, 1282-1295. https://doi.org/10.1016/j.jmb.2007.04.013.

Forrellad, M.A., Klepp, L.I., Gioffré, A., Sabio y García, J., Morbidoni, H.R., de la Paz Santangelo, M., Cataldi, A.A., Bigi, F., 2013. Virulence factors of the Mycobacterium tuberculosis complex. Virulence 4, 3-66. https://doi.org/10.4161/viru.22329.

Garnier, T., Eiglmeier, K., Camus, J.-C., Medina, N., Mansoor, H., Pryor, M., Duthoy, S., Grondin, S., Lacroix, C., Monsempe, C., Simon, S., Harris, B., Atkin, R., Doggett, J., Mayes, R., Keating, L., Wheeler, P.R., Parkhill, J., Barrell, B.G., Cole, S.T., Gordon, S.V., Hewinson, R.G., 2003. The complete genome sequence of Mycobacterium bovis. Proc. Natl. Acad. Sci. U. S. A. 100, 7877-7882. https://doi.org/10.1073/pnas. 1130426100.

Jones, G.J., Gordon, S.V., Hewinson, R.G., Vordermeier, H.M., 2010. Screening of predicted secreted antigens from Mycobacterium bovis reveals the immunodominance of the ESAT-6 protein family. Infect. Immun. 78, 1326-1332. https://doi.org/10.1128/ IAI.01246-09.

Knudsen, N.P.H., Nørskov-Lauritsen, S., Dolganov, G.M., Schoolnik, G.K., Lindenstrøm, T., Andersen, P., Agger, E.M., Aagaard, C., 2014. Tuberculosis vaccine with high predicted population coverage and compatibility with modern diagnostics. Proc. Natl. Acad. Sci. U. S. A. 111, 1096-1101. https://doi.org/10.1073/pnas. 1314973111.

Mawuenyega, K.G., Forst, C.V., Dobos, K.M., Belisle, J.T., Chen, J., Bradbury, E.M., Bradbury, A.R.M., Chen, X., 2005. Mycobacterium tuberculosis functional network analysis by global subcellular protein profiling. Mol. Biol. Cell 16, 396-404. https:// doi.org/10.1091/mbc.E04-04-0329.

Meikle, V., Bianco, M.V., Blanco, F.C., Gioffré, A., Garbaccio, S., Vagnoni, L., Di Rienzo, J., Canal, A., Bigi, F., Cataldi, A., 2011. Evaluation of pathogenesis caused in cattle and guinea pig by a Mycobacterium bovis strain isolated from wild boar. BMC Vet. Res. 7, 37. https://doi.org/10.1186/1746-6148-7-37.

Michel, A.L., Venter, L., Espie, I.W., Coetzee, M.L., 2003. Mycobacterium tuberculosis infections in eight species at the National Zoological Gardens of South Africa, 1991-2001. J. Zoo Wildl. Med. 34, 364-370. https://doi.org/10.1638/02-063.

Nishibe, C., Canevari Castelão, A.B., Dalla Costa, R., Pinto, B.J., Varuzza, L., Cataldi, A.A., Bernardelli, A., Bigi, F., Blanco, F.C., Zumárraga, M.J., Almeida, N.F., Araújo, F.R., 2013. Draft genome sequence of Mycobacterium bovis 04-303, a highly virulent strain from Argentina. Genome Announc. 1. https://doi.org/10.1128/genomeA. 00931-13.

Parks, D.H., Imelfort, M., Skennerton, C.T., Hugenholtz, P., Tyson, G.W., 2015. CheckM: assessing the quality of microbial genomes recovered from isolates, single cells, and metagenomes. Genome Res. 25, 1043-1055. https://doi.org/10.1101/gr.186072. 114.

Pluskal, T., Castillo, S., Villar-Briones, A., Orešič, M., 2010. MZmine 2: modular framework for processing, visualizing, and analyzing mass spectrometry-based molecular profile data. BMC Bioinformatics 11. https://doi.org/10.1186/1471-2105-11-395.

Roberts, D.M., Personne, Y., Ollinger, J., Parish, T., 2013. Proteases in Mycobacterium tuberculosis pathogenesis: potential as drug targets. Future Microbiol. 8, 621-631. https://doi.org/10.2217/fmb.13.25.

Sartain, M.J., Dick, D.L., Rithner, C.D., Crick, D.C., Belisle, J.T., 2011. Lipidomic analyses of Mycobacterium tuberculosis based on accurate mass measurements and the novel “Mtb LipidDB". J. Lipid Res. 52, 861-872. https://doi.org/10.1194/jlr.M010363.

Sassetti, C.M., Boyd, D.H., Rubin, E.J., 2003. Genes required for mycobacterial growth defined by high density mutagenesis. Mol. Microbiol. 48, 77-84. https://doi.org/10. 1046/j.1365-2958.2003.03425.x.

Sirakova, T.D., Dubey, V.S., Kim, H.J., Cynamon, M.H., Kolattukudy, P.E., 2003. The largest open reading frame (pks12) in the Mycobacterium tuberculosis genome is involved in pathogenesis and dimycocerosyl phthiocerol synthesis. Infect. Immun. 71, 3794-3801. https://doi.org/10.1128/IAI.71.7.3794-3801.2003.

Sreejit, G., Ahmed, A., Parveen, N., Jha, V., Valluri, V.L., Ghosh, S., Mukhopadhyay, S., 2014. The ESAT- 6 protein of Mycobacterium tuberculosis interacts with beta-2-microglobulin (??2M) affecting antigen presentation function of macrophage. PLoS Pathog. 10. https://doi.org/10.1371/journal.ppat.1004446.

Stadthagen, G., Korduláková, J., Griffin, R., Constant, P., Bottová, I., Barilone, N., Gicquel, B., Daffé, M., Jackson, M., 2005. p-Hydroxybenzoic acid synthesis in Mycobacterium tuberculosis. J. Biol. Chem. 280, 40699-40706. https://doi.org/10. 1074/jbc.M508332200.

Stewart, G.R., Wernisch, L., Stabler, R., Mangan, J.A., Hinds, J., Laing, K.G., Butcher, P.D., Young, D.B., 2002. The heat shock response of Mycobacterium tuberculosis: linking gene expression, immunology and pathogenesis. Comp. Funct. Genomics 3 (4), 348-351. https://doi.org/10.1002/cfg.183.

Stover, C.K., De La Cruz, V.F., Fuerst, T.R., Burlein, J.E., Benson, L.A., Bennett, L.T. Bansal, G.P., Young, J.F., Lee, M.H., Hatfull, G.F., Snapper, S.B., Barletta, R.G., Jacobs, W.R., Bloom, B.R., 1991. New use of BCG for recombinant vaccines. Nature 351, 456-460. https://doi.org/10.1038/351456a0.

Van Ingen, J., Rahim, Z., Mulder, A., Boeree, M.J., Simeone, R., Brosch, R., van Soolingen, D., 2012. Characterization of Mycobacterium orygis as M. tuberculosis complex subspecies. Emerg. Infect. Dis. 18, 653-655. https://doi.org/10.3201/eid1804. 110888 .

Van Soolingen, D., Hermans, P.W., de Haas, P.E., Soll, D.R., van Embden, J.D., 1991. Occurrence and stability of insertion sequences in Mycobacterium tuberculosis complex strains: evaluation of an insertion sequence-dependent DNA polymorphism 
as a tool in the epidemiology of tuberculosis. J. Clin. Microbiol. 29, 2578-2586. Vargas-Romero, F., Mendoza-Hernández, G., Suárez-Güemes, F., Hernández-Pando, R., Castañón-Arreola, M., 2016. Secretome profiling of highly virulent Mycobacterium bovis 04-303 strain reveals higher abundance of virulence-associated proteins. Microb. Pathog. 100, 305-311. https://doi.org/10.1016/j.micpath.2016.10.014.

Vázquez, C.L., Bianco, M.V., Blanco, F.C., Forrellad, M.A., Gutierrez, M.G., Bigi, F., 2017.
Mycobacterium bovis requires P27 (LprG) to arrest phagosome maturation and replicate within bovine macrophages. Infect. Immun. 85. https://doi.org/10.1128/IAI 00720-16.

Wobeser, G., 2009. Bovine tuberculosis in Canadian wildlife: an updated history. Can. Vet. journal. La Rev. vétérinaire Can. 50, 1169-1176. 